\title{
Donald Pierson e a escola sociológica de Chicago no Brasil: os estudos urbanos na cidade de São Paulo (1935-1950) ${ }^{1}$
}

EDGAR S. G. MENDOZA*

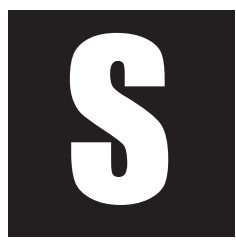
abemos que a cidade é o lugar de pesquisa dos estudos urbanos de vários campos científicos, entre eles os campos da Antropologia e Sociologia dedicados às pesquisas dos grupos sociais que moram na cidade. A pesquisa urbana no Brasil tanto sociológica quanto antropológica teve referenciais teóricos que deixaram sua influência nos trabalhos da época. No meu argumento, se pensarmos nos campos científicos da Antropologia e Sociologia Urbana no Brasil, as suas tendências teóricas foram influenciadas por três escolas de pensamento, em diferentes momentos históricos e teóricos, a Escola Sociológica de Chicago, a Escola Antropológica de Manchester, e a Escola Marxista Francesa de Sociologia Urbana, coexistindo simultaneamente suas produções intelectuais.

Este artigo, em termos amplos, trata da influência de Donald Pierson, formado na Escola Sociológica de Chicago, sobre a pesquisa urbana no Brasil nos anos 40 e 50, tanto na Sociologia quanto na Antropologia, na cidade

\footnotetext{
* Doutor em Ciências Sociais pela UNICAMP de São Paulo Brasil, Mestre em Antropologia Social pela Universidade de Brasília. Atualmente é pesquisador do Instituto de Investigaciones de la Escuela de Historia de la Universidad de San Carlos de Guatemala. Acadêmico de Número da Academia de Geografia e Historia de Guatemala e membro da Junta Diretiva de la Asociación Latinoamericana de Sociología -ALAS- período (2003-2005). E-mail: esgmendoza@yahoo.es

1 O artigo é uma síntese de um capítulo da minha Tese de Doutorado: Sociologia da Antropologia urbana no Brasil: a década de 70. IFCH-UNICAMP. São Paulo-Brasil. 2000.
} 
de São Paulo. ${ }^{2}$ Em um segundo momento, realizo estudos precursores nessa mesma cidade, na década de 40-50, tomados como um antecedente dos campos da Sociologia e Antropologia Urbana no Brasil. Com este objetivo em mente, mergulhei em várias bibliotecas em busca de pesquisas que tratassem da cidade e comprovassem a influência da Escola de Chicago, com o objetivo de encontrar estudos precursores feitos antes da construção do campo científico da pesquisa urbana no Brasil nos anos 70. A importância do artigo radica na ampla bibliografia encontrada e apresentada no final do texto sobre a influência da Escola de Chicago e sua repercussão no Brasil.

\section{Chicago em São Paulo: estudos precursores na cidade}

Este tópico trata de um resgate de pesquisas precursoras de estudos urbanos na cidade de São Paulo, as quais sofreram influência da Escola de Chicago e que, apesar de serem pesquisas isoladas, enfatizaram questões propriamente urbanas. O motivo de trazê-las é demonstrar que realmente foram um antecedente dos estudos urbanos no Brasil entre 1940-1950. Proponho, então, que a Sociologia da Escola de Chicago teve influência em três campos no Brasil: a) relações raciais (negros, brancos e imigrantes), ${ }^{3}$ b) estudos de comunidade (pequenas cidades rurais) ${ }^{4}$ e c) estudos na cidade (principalmente São Paulo). Embora os três campos sejam importantes, da-

\footnotetext{
2 O leitor interessado na Escola Sociológica de Chicago pode consultar os livros e artigos de revista que consultei, na ampla bibliografia no final do artigo.

3 Centrar-me-ei em Donald Pierson e a influência de Chicago nos seus estudos de relações raciais afro-brasileiras, pois com ele se institucionaliza este tema em São Paulo, como veremos depois. No entanto, no Brasil já existiam trabalhos em áreas urbanas, como as pesquisas seminais de Rodrigues [1932] (1982), Freyre [1936] (1977) do mesmo modo que Congressos AfroBrasileiros, o primeiro em Recife em 1934, e o segundo na Bahia, em 1937, mostram o interesse nas relações raciais no Brasil antes de Pierson. Sobre a história dos estudos de relações raciais desde 1940, consultem-se os aprofundados trabalhos de Guimarães (1995, 1999a, 1999b) e Bastide e Fernandes. [1955] (1959), Vila Nova (1995), livro que mostra a influência da Escola de Chicago através do pragmatismo em Gilberto Freyre.

4 Desenvolvidos principalmente em pequenas cidades do interior do Brasil nos estados de Bahia, Minas Gerais, São Paulo e outros. Sobre estes estudos não me estenderei, porque existem diversos trabalhos aprofundados que permitem sua analise e crítica (Ver análises de vários autores na bibliografia no final do texto).
} 
rei ênfase ao campo dos estudos na cidade de São Paulo, como veremos mais adiante.

Depois da revoluções de 30 e 32, o clima intelectual e político mudou e trouxe transformações pricipalmente na educação superior. A institucionalização das Ciências Sociais no Brasil se expressou na fundação de instituições que contaram na sua estrutura de ensino com as disciplinas de Sociologia e Antropologia. A criação da Escola Livre de Sociologia e Política, fundada em 1933, na Faculdade de Filosofia, Ciências e Letras da USP e da cátedra de Antropologia Social na Universidade do Distrito Federal criada em 1935, foram iniciativas da "geração precursora" que institucionalizou o ensino superior da Sociologia e da Antropologia no Brasil.

A institucionalização das Ciências Sociais no Brasil foi a condição que permitiu o desenvolvimento do pensamento social nesse período. Nesta geração precursora, destaca-se Donald Pierson e seu livro, Brancos e pretos na Bahia escrito na cidade de Salvador entre $1935-37 .{ }^{5}$ O porquê da escoIha? Na minha opinião, foi o primeiro trabalho com uma influência clara da Escola de Chicago no Brasil, que é o que me interessa na tese, com teoria, método de pesquisa de campo, etnografia e observação participante. Apesar de ter sido uma pesquisa de relações raciais e não da cidade de Salvador, a sua importância se deve ao fato de que inovou os estudos sociológicos no final da década de 30, principalmente em São Paulo. ${ }^{6}$

Apesar da amplitude de sua análise e dos temas analisados no livro, eu gostaria de enfatizar a metodologia de pesquisa de Pierson, centrandome nas suas notas metodológicas. ${ }^{7}$ O procedimento de Pierson na pesquisa de campo é muito diverso, vejamos, então, dois pontos importantes:

\footnotetext{
5 Pierson, Donald. [1942] (1971). Brancos e pretos na Bahia: estudo de contato racial. SP:Companhia Editora Nacional. 2a. edição. 6 Uma outra pesquisa desenvolvida em áreas urbanas de Salvador e que gostaria de mencionar foi feita em 1938 e 1939 por Landes, Ruth. [1947] 1967. A cidade das Mulheres. RJ:Civilização Brasileira.

7 Pierson (ibid.:390-398) no apêndice D: "Estudo de contato racial no Brasil: procedimentos de pesquisa". A experiência teórica e metodológica de Pierson converteu-se em livro, editado pela primeira vez em 1945. Teoria e pesquisa em Sociologia. SP: Edições Melhoramentos. Vol. 30 da "Biblioteca de Educação".
} 
a) Valendo-se da etnografia e da observação participante, ele fez uma descrição minuciosa da situação racial, analisou o número proporcional de indivíduos em contato, graus de prestígio, segregação racial e miscigenação, ocupações, vestuário, atitudes do grupo, função do mestiço na comunidade, participação de grupos sociais, ecologia, economia, política e sociologia das relações entre grupos, a consciência de raça, status, sentimentos grupais de segregação e formas culturais.

b) Com a observação participante, as técnicas de pesquisa de seleção de informantes principais (homens, mulheres, idade, etc.), técnicas de questionários, árvores genealógicas, entrevistas diretas, ele obteve, de primeira mão, dados importantes. O registro de rituais, casamentos, cerimônias, concertos musicais, acontecimentos esportivos, solenidades, festas populares, desfiles, abertura e encerramento de festas de escolas, igrejas, missas, homenagens, inaugurações, clubes, cinemas, recepções, congressos, carnavais, procissões, bibliotecas públicas e escolas, Pierson conseguiu ter uma idéia geral dessas situações temáticas. Alem disso, os seus estudos em arquivos históricos na procura de documentos, mapas da cidade, documentos pessoais (cartas), autobiografias, censos demográficos, histórias de vida, classificações (provérbios), jornais, bibliografias científicas, literatura popular (romances, poesias, contos etc.), permitiram-lhe reconstruir o passado de Salvador.

Pierson incorpora-se, em 1939, à Escola Livre de Sociologia e Política, criada em 1933 e, em 1941, cria a Divisão de Estudos Pós-Graduados, ${ }^{8}$

\footnotetext{
8 Entre os melhores trabalhos sobre a trajetória intelectual de Donald Pierson e sua presença institucional , consulte-se o depoimento publicado por Corrêa (1987), Massi (1989), Oliveira Lippi (1987) e Nogueira (1970). Aliás encontra-se o acervo de Donald Pierson que consiste em várias pastas (documentos acadêmicos e pessoais) no Arquivo Edgard Lehuenroth (AEL)UNICAMP, nas quais as cartas pessoais são uma constante correspondência entre Pierson e Robert Park a quem Pierson prezava muito. Também vale a pena mencionar as entrevistas e depoimentos em vídeo de Müller, Antonio Rubbo. Arquivo Edgard Lehuenroth (AEL)UNICAMP. 1984. 1 Videocassette, Son, Color, VHS-Palm-M (50 minutos) e de Chiara, Vilma. Arquivo Edgard Lehuenroth (AEL)UNICAMP. 1984. 1 Videocassette, Son, Color, VHS-Palm-M (51 minutos).
} 
dando, assim, início à formação de alunos e discípulos através de aulas, seminários, conferências, traduções de livros e artigos, contatos com instituições, universidades e professores estrangeiros. O programa de Pierson incluía a ida de seus alunos ao exterior, como foi o caso de Mário Wagner Vieira da Cunha, Oracy Nogueira, Juares Brandão Lopes e Levy Cruz, para a Universidade de Chicago e outros, para diversas universidades, Esta foi uma maneira de treinar profissionais capacitados, mas, ao mesmo tempo, de reprodução e construção de uma maneira de fazer pesquisa no Brasil.

Um dos sociólogos e antropólogos brasileiros de destaque, no final dos anos 40 e décadas seguintes, foi Oracy Nogueira, que entre suas influências teóricas conta com Pierson e a Escola de Chicago. ${ }^{9}$ Nogueira estudou na Universidade de Chicago entre 1945-47, época em que a terceira geração, como Herbert Blumer e Everett Hughes, ${ }^{10}$ ensinava nessa universidade.

A influência de Chicago no Brasil se efetivou com Donald Pierson, que foi o principal divulgador das teorias da Escola de Chicago em São Paulo. Quais as características dessa influência? Pierson foi figura central e tinha seus seguidores; possuidor de forte personalidade e grande carisma como intelectual inovador com novas idéias, pontos de vista e orientações. $\mathrm{Na}$ Escola de Sociologia e Política, Pierson treinou várias gerações de pesquisadores. Está mais que demonstrada a influência da Escola de Chicago na Sociologia brasileira, e, como escrevi antes, está presente nos campos das relações raciais e nos clássicos estudos de comunidade, em pesquisas localizadas em áreas rurais. Contudo os estudos sobre comunidade não podem ser considerados como Sociologia Urbana, apesar de que tenham

\footnotetext{
9 Sobre a trajetória de Oracy Nogueira existe o acervo e uma entrevista no Arquivo Edgard Lehuenroth (AEL)UNICAMP. 1984. 1 Videocassette, Son, Color, VHS-Palm-M, (35 minutos), além disto, Cavalcanti (1996a, 1996b, 1999) e a autora que tem trabalhado a história intelectual de Nogueira.

10 No acervo Donald Pierson. Arquivo Edgard Lehuenroth (AEL)UNICAMP, encontram-se várias cartas pessoais entre Oracy Nogueira e Pierson, época em que Nogueira estava estudando em Chicago, que mostra não só a amizade, mas a relação acadêmica entre os dois. Os dois acervos, Pierson-Nogueira são fontes primárias para futuras pesquisas sobre a trajetória dos dois cientistas.
} 
sido feitos alguns trabalhos sobre imigrantes, com o referencial teórico da assimilação e aculturação. A Escola de Chicago está presente nos estudos de comunidade, porém a falta de pesquisas na cidade é ressaltada. Voltando ao meu argumento do início do tópico quando me referi aos estudos precursores em São Paulo, defino-os como os efetuados em áreas urbanas na cidade. O que pretendo é verificar a hipótese da influência da Escola de Chicago principalmente na década de 40, em pesquisas concretas. Apesar de serem poucas, eram ao meu ver etnografias urbanas na cidade. ${ }^{11}$

\section{Estudos urbanos em São Paulo}

Portanto, estou pensando a cidade de São Paulo como um cenário em termos gerais, não como estudos, como uma agenda de pesquisa institucional nos anos 40-50. Seria arriscado defini-los nesta época como Sociologia Urbana propriamente dita em São Paulo, ${ }^{12}$ embora tenham sido realizados trabalhos demográficos como sobre o padrão de vida dos operários e sobre população étnica nessa cidade de São Paulo. ${ }^{13}$

Diferente dos trabalhos demográficos, entre as poucas e modestas pesquisas de Sociologia na cidade de São Paulo tomada como objeto de estudo, foi feita uma etnografia na cidade. As pesquisas que posteriormente analisarei foram escolhidas pelo fato de terem a influência da Escola de

\footnotetext{
11 A importância do estudo da cidade desde um ponto de vista teórico fica explicita em Pierson, Donald. 1943. "O estudo da cidade". Sociologia. Vol. V, n. 4, p. 305-315, influenciado pelos textos de Robert Park, define a cidade como um produto natural, ordem moral, mundos mentais e áreas naturais.

12 No Rio de janeiro também temos uma pesquisa urbana inicial entre 1940-1950, mas não como uma Sociologia urbana nem influenciada pela Escola de Chicago; são trabalhos principalmente sobre favelas, publicados em jornais e relatórios, como por exemplo, Pearse (1958). Para uma bibliografia sobre a favela no Rio de Janeiro, Cf. Parisse (1969).

13 Gostaria de mencionar quatro trabalhos demográficos sobre alguns temas da cidade de São Paulo, apesar de não serem sociológicos, foram trabalhos demográficos precursores. Os primeiros dois sobre operários como, Davis (1935), trabalho feito em base de estatísticas, já que respondia a um trabalho demográfico. O segundo, Lowrie (1938b), trabalho interessante, principalmente nos métodos de pesquisa demográficos e nos questionários que foram passados por um grupo de pessoas treinadas. Os dois seguintes, foram trabalhos de população étnica de São Paulo, o primeiro, foi de Souza (1937), este trabalho é denominado
} 
Chicago e terem sido realizadas na cidade de São Paulo, definindo-as como uma etnografia na cidade ou como uma etnografia urbana diferente dos clássicos estudos de comunidades em pequenas cidades rurais. Temos inicialmente oito trabalhos que foram publicados principalmente como artigos em revistas, sendo o objeto de pesquisa alguns bairros da cidade, ou outras cidades.

Em primeiro lugar, gostaria de começar com um trabalho de Lucila Hermann de 1938. ${ }^{14}$ A cidade de Guaratinguetá está localizada ao norte de São Paulo. Embora a pesquisa não tenha sido feita necessariamente na grande São Paulo, a tentativa de fazer um estudo da cidade tem seu mérito. Aliás, a influência de várias categorias teóricas da Escola de Chicago estão presentes: esta foi uma pesquisa descritiva, mas com muita informação sobre as áreas urbanas. Porém o trabalho não pode ser considerado como um estudo de comunidade, já que seu ponto central foram as áreas naturais da cidade de Guaratinguetá.

Nessa pesquisa, descrevem-se as diversas áreas como as áreas culturais da região central (comércios), da zona residencial (casas de luxo), da zona suburbana (bairros), que, por sua vez, subdividem-se em cinco zonas diferentes, todas localizadas com os nomes das ruas, assim como com informação do número de empregados nas fábricas, os comércios de pequenas lojas, sendo os donos pertencentes às minorias étnicas entre as quais existia uma "competição", como diria R. Park. (p. 73-77). Além disso, Hermann fez uma descrição das ruas e avenidas e das áreas morais, formadas pela mendicância e meretrício, na sua maioria de baixo nível econômi$\mathrm{CO}$, com a presença de mendigos, andantes e meretrizes e sua localização em ruas e bairros.

\footnotetext{
por Souza como biotipológico com categorias como miscigenação, ancestrais e outras, foi um estudo quantitativo que determinava de que etnias descendiam os alunos da USP, entre elas a italiana, portuguesa, síria, alemã etc. O segundo trabalho de Lowrie (1938a), trabalho demonstrou através de categorias como geração, origem e casamentos entre brasileiros e estrangeiros a porcentagem como ele chama de cruzamentos entre estes indicando a mudança de status social e diferenças de condições econômicas. Para ele o preconceito de classe parece ter contribuído mais do que o de raça para a formação desta situação. 14 Hermann, Lucila. 1938. "Grupos sociais de Guaratinguetá". Revista do Arquivo Municipal. Vol. XLIX:71-92, o artigo está acompanhado por 24 fotografias de residências das várias zonas descritas.
} 
A descrição por zonas é uma aplicação do modelo do círculo de zonas concêntricas de Burgess, de igual forma a ordem de apresentação das áreas é do centro para a periferia. Hermann descreve a zona comercial, indicando as três Guaratinguetás: a) a moderna (arquitetura nova); b) a cosmopolita (presença de minorias nacionais como italianos, sírios, espanhóis, portugueses e judeus) (p. 82); c) a heterogênea, formada por uma multiplicidade de grupos religiosos e grupos sociais e a sua mobilidade, assim como o nível econômico e relações sociais. Uma outra divisão de Hermann, consistiu nas zonas residenciais de luxo e nas de residências modestas. As primeiras seriam as residências de luxo, cujas construções, demografia, nível econômico e relações sociais ele descreve minuciosamente (p. 83-85). As segundas, consistiriam nas residências modestas, representadas por casas antigas, na sua demografia, mobilidade, cultura, profissões, lazer, política e religião (p. 85-88) As pesquisas sobre as zonas urbanas mostram dados sobre casas antigas, humildes, sobre aspectos demográficos, religiosos (casamentos, missas e igrejas), uma maior mobilidade profissional pelo fato do pouco trabalho, relações sociais de vizinhança, baixo nível cultural e segregação (p. 89-92). Finalmente, descrevem os usos e costumes. Nesse trabalho, foram aplicados testes sociológicos e entrevistas, com o objetivo de conhecer "a vida da cidade", através de comportamentos, mentalidades e crenças. A amostra foi formada por 93 indivíduos (idosos e chefes de família), 4 na região comercial, 64 indivíduos divididos em 6 nas residências de luxo , 58 nas residências modestas e 25 na área suburbana.

O questionário incluía as perguntas sobre habitação, arquitetura, família, casas alugadas ou próprias, alimentação, renda, estudo, nascimento, mobilidade profissional e política. A meu ver, um trabalho pioneiro de pesquisa urbana da cidade, com uma metodologia de trabalho de campo e uma abordagem sociológica. $\mathrm{O}$ artigo não apresenta a grande quantidade de material que Hermann coletou, assim como através da metodologia, 
verifica-se a influência evidente da Escola Sociológica de Chicago, principalmente no trato dos dados e das categorias teóricas. O trabalho de Hermann é contemporâneo ao de Pierson na Bahia, entre 1935-1937, mostrando uma influência inicial da Escola de Chicago.

Nota-se, ainda, a tentativa de semelhança entre São Paulo e Chicago, esta última como um modelo a ser imitado, principalmente quanto ao quarteirão como medida de planejamento urbano. No entanto, ficaria como uma referência. A Escola de Chicago e a cidade de Chicago foram um referencial que marcou teoricamente os primeiros trabalhos sociológicos. Apesar da influência teórica da escola, ela não foi um modelo de identidade para os sociólogos no Brasil, para formar uma escola de pensamento com essa linha teórica.

O segundo artigo foi de Araújo, em 1940, ${ }^{15}$ o qual indicou a cidade de São Paulo como um "campo de estudos de problemas étnicos" com uma variedade de grupos sociais de vários países. O hinterland paulista constituiu um centro de pesquisa inesgotável, delimitando o município da capital como zona de pesquisa (p. 229). A pesquisa de Araújo consistiu, em termos gerais, no estudo da assimilação, ou dos imigrantes na cidade de São Paulo e seus lugares de habitação ou, como ele chama, de "enquistamentos étnicos" ou áreas naturais, com a finalidade de que a pesquisa desses grupos pudesse orientar a política de imigração na cidade de São Paulo.

As questões discutidas no trabalho foram: a) o estudo do grau de interfusão das nacionalidades que formam o povo brasileiro; b) determinação dos coeficientes de homogeneidade de cada etnia no conjunto de famílias que não sofrerem processo de assimilação; c) determinação dos caracteres físicos e psicológicos resultantes das interfusões e d) pesquisas detalhadas 
com caráter biológico e social nos enquistamentos encontrados (p. 228).

A metodologia foi uma "observação in locu", como ele chama, da distribuição ecológica dos enquistamentos, à maneira de guetos ( p. 230). A etnografia foi definida como uma "verificação olhométrica" (p. 237), notando-se, no texto, a presença dos base map e melting pot, bem como as chamadas zonas concêntricas de Burgess. A pesquisa foi feita em três bairros, distribuídos em quarteirões dos grupos sírio, japonês e judeu e incluindo outras nacionalidades. No texto, observa-se a influência ecológica com as categorias, aclimatação, habitat e zona ecológica.

A riqueza do texto está precisamente na etnografia urbana feita por Araújo, no detalhe e descrição dos bairros , nomes de avenidas, farmácias, hotéis, restaurantes, entre-cruzamentos de ruas, comidas, livrarias, lojas, mesquitas, a língua falada como o jiddisch no bairro judeu, estatísticas por sexo, etnia nos distritos, os ramos industrias definidos por rua, e etnia e suas porcentagens. As conclusões do estudo indicavam o grau de assimilação das etnias, os casamentos entre eles e a integração cultural ao meio brasileiro, as tendências à concentração de alguns grupos de imigrantes, as tendências endogâmicas e exogâmicas dos descendentes. O artigo, apesar de curto, é representativo de pesquisas na cidade. ${ }^{16}$

Um terceiro trabalho foi de Willems, $1941,{ }^{17}$ que começa com uma discussão da vizinhança como categoria analítica na Sociologia ou como unidade social originada pelo próprio espaço, indicando uma distância geográfica e social nas zonas ecológicas (p. 29). A vizinhança foi utilizada como uma unidade menor nas relações sociais na cidade, tal como foi proposto por Weber, categoria teórica desenvolvida posteriormente por Park, e procurada empiricamente por R. McKenzie no seu estudo da vizinhança em Columbus, Ohio.

\footnotetext{
16 Uma pesquisa que não posso deixar de mencionar foi feita em 1941 por Florestan Fernandes sobre as "trocinhas" e a coleta de canções de ninar e ditados folclóricos, Fernandes (1961) "As trocinhas do bom retiro: contribuição ao estudo folclórico e sociológico da cultura dos grupos infantis", no Folclore e mudança social na cidade de São Paulo. Aliás, os outros trabalhos da coletânea são importantes porque mostram o detalhe na coleta do material.

17 Willems, Emílio. 1941. “Contribuição para uma Sociologia da vizinhança”. Sociologia. Vol. 3, n. 1, p. 29-43.
} 
Para Willems, existem dois grupos vicinais: a) vizinhança igualitária (coordenativa) e b) vizinhança senhorial (subordinativa), no qual o aspecto econômico é importante junto com as relações vicinais, simbiose, competição, reciprocidade, necessidades e parentesco (consangüíneo, totêmico, classificatório) (p. 31). Willems faz uma pequena comparação com grupos indígenas e fundamenta que a vizinhança pode substituir tribo ou clã, já que, na vizinhança, continuam os laços de parentesco, propriedade, religião e espaço.

Willems sugeriu chamar de vizinhança concomitante aquela em que a propriedade do espaço é reduzida e indicou que "certas pessoas são parentes por ter sido vizinhos e não vizinhos por serem parentes" (p. 32), permitindo a existência de uma interação coletiva. Contudo a vizinhança existencial seria aquela isolada na qual aconteceria uma endogamia forçada. Para Willems, a urbanização trouxe a convivência entre vizinhos, como se fossem estranhos e as relações vicinais passam para planos secundários da vida social (p. 33). Isto bem poderia ser a desorganização social proposta por Park e Thomas, de Chicago.

A segunda parte do artigo de Willems foi denominada de ensaio de inquérito sobre relações vicinais em São Paulo. Começa dizendo que as relações vicinais nas áreas metropolitanas são uma incógnita, como por exemplo: a) os moradores de bairros residenciais da alta burguesia têm um certo desprezo pelas relações vicinais, e a segregação social e a distinção social são visíveis; b) as casas de pequena e média burguesia não têm áreas internas que não permitem segregação, mantendo maiores contatos na rua e c) a habitação proletária se caracteriza pela sociabilidade e solidariedade, 
embora os conflitos entre vizinhos sejam mais freqüentes (p. 34, 35).

Com essas propostas tomadas como hipóteses de trabalho, Willems fez uma pesquisa ou inquérito, como ele prefere chamar, das relações vicinais em 1939 e $1940 .{ }^{18}$ A confecção do questionário teve as seguintes hipóteses de trabalho: 1) as relações vicinais variam em função da natureza do bairro; 2) as relações vicinais variam de classe social; 3) as relações vicinais variam de nacionalidade e 4) as relações vicinais conduzem à transmissão de dados culturais (p. 35). Uma outra hipótese foi a de que bairros habitados pelos componentes da mesma classe social poderiam apresentar diferenças decorrentes de fatores, como distância do centro urbano, transportes e oportunidades.

No que tange a elementos determinantes da classe social, Willems considerou a profissão do chefe da casa, o número de empregados e a circunstância de se tratar de casa própria ou alugada. A utilização de um questionário permitiu obter uma série de dados qualitativos e quantitativos valiosos. O questionário teve três seções principais: a) relações amistosas; b) relações hostis e c) indiferença. Além disso, utilizaram-se dois modelos de questionário, o modelo " $\mathrm{A}$ ", que consistia numa família específica, e o modelo "B", as outras famílias vicinais (p. 36, 37).

A parte essencial da pesquisa tratou dos dados culturais e sua transmissão sendo que, no modelo " $\mathrm{A}$ ", predominam as classes médias, e no modelo "B", os bairros proletários (ver questionário). No artigo de Willems aparece o modelo de questionário e, pela importância metodológica de conhecer um instrumento de coleta de dados, pensei em incluí-lo na tese, já que é, a meu ver, um documento valioso de uma técnica utilizada em 1941. A seguir, apresento o questionário do modelo " $\mathrm{A}$ " e do modelo "B"

18 Willems na sua nota de rodapé número 8 indicou que o inquérito foi realizado pelos alunos do curso profissional das Escolas Normais Osvaldo Cruz, Rio Branco e Ipiranga, com colaboração dos professores Romano Barreto e Querino Ribeiro. 
(nas páginas seguintes anexo os dois modelos de questionário).

Para encerrar o ensaio, Willems chama a atenção para futuras pesquisas mais bem desenvolvidas na cidade de São Paulo. Na minha opinião, este tipo de etnografias urbanas mostra uma época em que a cidade de São Paulo iniciou seu um desenvolvimento industrial e os movimentos migratórios para a cidade, a partir de 1930, formando os chamados bairros proletários. A indústria e a cidade foram parte importante do processo de urbanização de São Paulo.

O quarto trabalho, consistiu em um estudo sobre habitações feito por Pierson em 1942. ${ }^{19}$ Foi um estudo comparativo de acomodações de alojamento na cidade de São Paulo. Pierson esclarece que os dados obtidos podem ser utilizados por outras ciências tanto teóricas quanto aplicadas tais como a ecologia humana (luta pela existência), a Antropologia (tipos de moradia e costumes domésticas entre povos), a Sociologia (sistema de classes) (p. 200). A amostra foi coletada em habitações (prédios) e moradias (casas), através de dados censitários e de um questionário de 181 itens. As habitações foram definidas como: área "A" (nível inferior) e área "B" (nível superior), distribuídas em 200 habitações, 100 de cada área, com uma descrição de casas por bairro e de suas ruas. A área "A" (Bexiga, Moóca e Canindé) e área "B" (Jardim América, Pacaembu e Higienópolis) (p. 201). Os dados obtidos por Pierson (p. 203) são mostrados em 25 quadros, com um tema cada um.

O detalhe dos quadros, mostra o cuidado nos levantamentos dos dados, sendo que citei os quadros que mais especificidades mostraram. Todo este material foi tabulado, e se obtiveram freqüências e porcentagens. $\mathrm{O}$ resultado do trabalho de Pierson, em equipe, não apresenta muita interpre-

19 Pierson, Donald. 1942. "Habitações de São Paulo: estudo comparativo". Revista do Arquivo Municipal. Vol. LXXXI, p. 199-238, inclui fotografias. Além disso, segundo Pierson, o estudo tinha um objetivo pedagógico para os alunos do curso de métodos e técnicas de Ciências Sociais, da Escola Livre de Sociologia e Política. 
tação sobre os dados. Aparecem apenas 3 quadros e colunas, que comparam as áreas superiores e inferiores, mostrando claramente o status econômico da área superior em todos os elementos e as condições mínimas da área inferior. O material ficou para ser utilizado por outras áreas de conhecimento. Do mesmo modo, Pierson não explica como foi o trabalho de campo dos entrevistadores ou de alguma pesquisa etnográfica que foi feita, mas não incluída no texto.

A quinta pesquisa, semelhante à de Willems, foi feita por Heller em $1943,{ }^{20}$ em uma rua chamada Rua Nova, a doze quilômetros do centro da cidade de São Paulo, uma rua que começou a ser loteada para formar um bairro. Os primeiros habitantes eram portugueses e logo, alemães. Os detalhes da etnografia são ricos, como os dados sobre o tempo de viagem de bonde até a rua, o qual era de 32 minutos, e a viagem de ônibus era de 22 minutos; descreve-se também a distância da rua, em relação a algumas referências como o ponto de bonde a 380 metros, o posto policial a 50 metros, a farmácia a 800 metros, posto de telefone público a 1200 metros, consultório de um médico a 2300 metros. A rua tem 210 metros de comprimento e 16 de largura, é provida de luz elétrica em 1934, e de água em 1935, sendo que era habitada por uma pequena burguesia (p. 199, 200).

Heller não descreve a metodologia de coleta de dados, mas fez, a meu ver, uma etnografia urbana, analisou vários tópicos, todos eles com apresentação de tabelas estatísticas de freqüência, por exemplo: o status social das famílias burguesas e proletárias, preço da escola, serviços públicos (luz, ônibus e água), fatos ecológicos, luta pelo status social e espaço (competição, segundo Park), distribuição étnica e gerações. Além desses temas, pesquisou a descendência de casais, religião, casamentos, ingresso de salários, empregos familiares, índice de escolaridade e distância das casas.

Entre os temas mais particulares ou privados, Heller fez tabelas de compras e leituras de jornais das pessoas, leituras de outras áreas (poesia) e 
tipos de livros, tipos de enfeite nas casas, aparelhos de rádio, viagens das famílias e lugares, freqüência à igreja (católicos, protestantes, sinagoga, templo espírita), visitas de família, língua falada em casa, atividades de lazer e conflitos entre famílias. Nas suas conclusões, Heller manifestou que não conseguiu casos de uma vizinhança subordinativa, predominando os casos de vizinhança coordenativa, e cita o artigo de Willems, (1941) trabalho que mencionei em parágrafos atrás. Finalmente para Heller, "As relações não são muito influenciadas pela nacionalidade, mas sim pela posição social dos moradores e seus diferentes níveis culturais" (p. 213), isto é, o espaço, prestígio e posição econômica marcariam a diferença entre os vizinhos.

O sexto artigo foi feito por Hermann em 1944; ${ }^{21}$ segundo ela, existe um desenvolvimento ecológico da cidade de São Paulo em 490 anos, tendo como eixos centrais as suas radiais (entrada e saída da cidade) (p. 7). Hermann descreve cada uma das radiais e os nomes das ruas e seus cruzamentos, assim como os elementos agrícolas das radiais por onde passavam (p. 8), e faz o que ela chama de uma descrição ecológica do trajeto. Hermann, localiza as tendências do desenvolvimento ecológico de São Paulo (p. 8), através de: a) localizar nos mapas topográficos o trajeto das radias sul (caminho do mar) e a radial oeste (caminho do café); b)a direção do mar para o café (sul-oeste), indicando uma lista de avenidas e ruas, como a Augusta, Av. Europa, Av. Cidade Jardim rumo Pinheiros, Consolação, Av. Rebouças, etc. Segundo Hermann (p. 11), o desenvolvimento da cidade não se processou uniformemente, mas, ao contrário, espalhou-se muito irregularmente até os subúrbios.

Hermann sugere que o crescimento urbano de São Paulo, se deve a suas avenidas ecológicas de depressões geográficas que provocou um movimento urbano e construção de moradias públicas (p. 13). Ela mostra através de tabelas os preços das habitações em 1926, as áreas mais caras como 
a Av. São João e Av. Anhanguera. Em uma das tabelas (p. 16, 17), se mostra que entre 1911-1913 e 1926-1928, houve um investimento maior nas radiais aumentando o preço do aluguel nas principais avenidas. Toma como exemplo as áreas ecológicas na radial de São João Lapa mostrando os mudanças das área que são heterogêneas (p. 19-24), a distância desigual de índices ecológicos, surtos de valorização entre 1900-1940, a localização das áreas (aparência dos prédios), distribuição dos prédios, casas de luxo, casas em deterioro e parques industriais (p. 24-28).

Hermann, apresenta o que ela chamou de caraterísticas sociológicas das áreas ecológicas de São Paulo (p. 28-38). Trabalhando a distribuição demográfica, o centro econômico, político-administrativo, e a descrição de duas áreas e duas zonas, que a meu ver correspondem novamente ao modelo de zonas de Burges, vejamos: a) áreas de transição e deterioração social (final da Av. São João) (p. 31, 32) que seria a zona moral de Park, é neste ponto que a meu ver.

Hermann fez uma etnografia urbana, pois descreveu as relações morais e sociais, relações sociais, ocupações, zonas de meretrício, constante mobilidade social, e independência de locomoção. Esta área [a] foi considerada como uma área de segregação e vícios, onde a presença da polícia era constante; [b] área de residências modestas, habitada por uma classe média burguesa, como funcionários públicos, e onde existe um controle social por grupos religiosos, principalmente católicos, censura, família e um alto índice de proprietários de casas, c) zona de residências de luxo, formada pela alta burguesia (p. 36-38). Aí se teria um cosmopolitismo de um grupo de industriais, fortes capitais e uma mobilidade para o exterior. Hermann explica que muitas áreas que eram de luxo, no centro da cidade, por causa do movimento do comércio passaram a ser áreas de casas modestas, ou as casas foram para fora da cidade; d) as zonas suburbanas (p. 36-38) formadas por cidades satélites próximas a fábricas localizadas na periferia da cidade. Encontraremos aí um número de serviços públicos, comerciantes, laços de vizinhança, cooperação, menos educação e ocupações comerciais. 
A pesquisa de Hermann abrange vários aspectos, um deles foi o planejamento ecológico urbano na cidade de São Paulo nos anos 30 e 40, assim como a descrição das áreas e zonas de habitações tanto no centro quanto na periferia. Hermann conseguiu combinar análises gerais com análises particulares. Lamentavelmente a parte de pesquisa etnográfica qualitativa não está presente no texto. Além disso, a perspectiva de estudo lembra o referencial da Escola de Chicago, como por exemplo, a distribuição por zonas, tal como propôs Burgess.

A sétima pesquisa que refiro foi feita por Xidieh, em 1947,,22 em um subúrbio paulista no município de Mogi das Cruzes, pesquisando uma igreja e a história de vida de um pastor, o Sr. Narciso. O artigo começa descrevendo as áreas ecológicas da população suburbana como comércios, estradas, ruas, vilas proletárias, casas comerciais e a construção de bangalôs (que seria o equivalente à zona $\mathrm{V}$ de commuters proposto por Burgess). Xidieh (p. 174, 175) mencionou o homem suburbano e sua condição de marginal (podendo referir-se ao homem marginal de Park e de Stonequist). Xidieh escreveu sobre o inconsciente, a luta pela vida, comportamento individualista, ressentimento e crime, sobre uma espécie de desorganização social, como diria Thomas, ou competição, segundo Park.

Do mesmo modo que Willems e Heller, Xidieh não descreveu a metodologia que utilizou para a coleta dos dados, apesar de que mencione as fichas de entrevista com delinqüentes e moços criminosos, mas não as utilize neste artigo. No entanto, ele usa técnica de história de vida como é mostrado na trajetória do Sr. Narciso, um homem que, em 1938, convertese em pastor de uma igreja chamada Igreja Triunfante ou Católica Evangélica Militante. Xidieh descreveu em poucas linhas como se desenvolveu uma cerimônia dessa igreja em São Paulo, já que Narciso viajava para fazer os 
cultos. O curto artigo de Xidieh é bastante descritivo, mais do que interpretativo, contudo permite reconhecer as categorias analíticas tomadas dos trabalhos da Escola de Chicago.

Finalmente o oitavo trabalho desenvolvido por Nogueira em 1949²3 trata de um estudo sobre habitações de operários em São Paulo. Segundo Nogueira, a habitação não só é um elemento de conforto, mas pode também refletir o nível de aspirações dos moradores, os quais se estimulam ou se deprimem. A casa pressupõe aspectos culturais, sociais ou hábitos de vida, atividades e valores (p. 32). A urbanização no mundo todo tem modificado a concepção de casa na cidade. Para Nogueira (p. 33), nas cidades, a localização das casas está em relação com os locais de trabalho e com certas instituições como escolas, igrejas, centros de recreação, etc.

O objetivo do trabalho era estudar determinado ramo industrial (indústria têxtil), procurando-se o número de operários e estabelecimentos. Os operários eram paulistanos, e seus lugares de moradia, próximos das fábricas. Foram entrevistados 65 estabelecimentos localizados no leste de São Paulo, na radial norte-sul (p. 35). Dos 65 lugares, foram escolhidos 3 (Ipiranga, Hipódromo, Belenzinho), com 200 operários. Eles foram organizados por Nogueira em 100 lugares de habitação que ficassem a mais de 4000 mts. de distancia da fábrica, e outros 100 lugares que estivessem a menos de 4000 até 1000 mts. A finalidade era demonstrar que a mobilidade social dependia dos lugares de habitação e da proximidade do trabalho (p. 36). As entrevistas com os operários foram feitas por uma equipe, que observou o meio e a moradia localizada em uma área dos operários. Os resultados da pesquisa foram apresentados através de quadros (p. 37-44).

Nogueira detectou o problema de que o tempo de permanência na casa era determinado pelo emprego, isto é, os operários próximos, com 
casa própria, tinham maior tempo de emprego, enquanto os operários distantes alugavam e possuíam menor tempo de trabalho. Nogueira conclui que: a) existia uma importância da casa própria como fato de estabilidade no emprego, e b) aumento de alugueis de casa levava à mobilidade espacial do emprego (p. 44). Neste sentido, o trabalho de Nogueira foi pioneiro no estudo da habitação dos grupos operários e foi um trabalho quantitativo bem estruturado, com uma seleção das fábricas e dos lugares de moradia, isto é, o que, em Chicago, chamava-se de Base Map, na localização em termos gerais do objeto de estudo em relação à cidade

Para concluir, as oito etnografias urbanas feitas na cidade de São Paulo foram trabalhos fragmentados que não forneceram uma continuidade como temas e interesses em uma agenda de pesquisa. Mas permitiram observar a influência de Chicago nos anos 40, principalmente com Pierson em São Paulo, e que continuou na década de 50. Do mesmo modo, resgatar a existência de um corpo de pesquisas urbanas como antecedentes do campo intelectual permite conhecer os antecedentes dos estudos urbanos no Brasil.

Com relação à influência de Chicago, que esteve presente neste período de tempo inicial, esta voltaria ao Brasil, na década de 70, com o interacionismo simbólico. A ausência de Chicago nos anos 50 e 60 obedece a mudanças teóricas e históricas que mudaram os interesses de pesquisa, entre eles o problema urbano, o desenvolvimento, a influência do marxismo e o crescimento e fundação de instituições dedicadas a este aspecto como aconteceu nessas décadas, sendo este um tema para outro artigo.

\section{Conclusões}

Neste artigo fiz uma breve trajetória da Escola de Chicago como uma forte influência nas pesquisas urbanas no Brasil, tendo sido Donald Pierson, o principal transmissor da Escola de Chicago em São Paulo, formando duas gerações de pesquisadores que continuaram com influência no 
Brasil, ressaltando-se Orací Nogueira como um dos principais discípulos em São Paulo.

Os estudos precursores da cidade, feitos nos anos 40-50, são um antecedente direto do campo de pesquisas urbanas, as quais resgatei para demonstrar sua importância, e para que fossem integradas à história da pesquisa urbana no Brasil, ressaltando ainda mais o seu pioneirismo na procura do sujeito urbano na cidade. Estes anos foram o período em que a Escola Sociológica de Chicago teve influência sobre as pesquisas, como demonstrei na análise de oito trabalhos (1935-1950), principalmente no uso do modelo de zonas concêntricas de E. Burgess. Os trabalhos de L. Hermann, O. Araújo, E. Willems, D. Pierson, F. Heller, O. Xidieh e O. Nogueira, fizeram uma pesquisa detalhada de vizinhança, bairros, radiais, habitações, operários e ruas, sendo que mereciam ser resgatados do esquecimento.

Os oito trabalhos sobre a cidade de São Paulo, não os considero propriamente como estudos de Sociologia Urbana, mas como antecedentes, já que não existia uma agenda institucional de pesquisa. Foram tentativas de aproximação ao estudo da cidade e do sujeito social habitante dela, pois, apesar dos esforços isolados não institucionalizados, a cidade não era ainda compreendida como objeto de estudo significativo. A Escola de Chicago foi a primeira escola a exercer influência sobre estas pesquisas urbanas. De uma perspectiva ecológica em certos momentos, e em outros, como uma Sociologia Urbana, combinando várias teorias e autores, principalmente europeus, essa Escola influiu em trabalhos no Brasil, tais como os de relações raciais (negros, brancos e imigrantes), como os das categorias de aculturação e assimilação, os estudos de comunidade que tiveram uma grande importância no Brasil e outros países do mundo, com uma preocupação nas migrações campo-cidade, principalmente em três campos: a) no das relações raciais, b) no dos clássicos estudos de comunidade e c) nos estudos precursores na cidade de São Paulo em que centrei a minha atenção. 


\section{Referências}

ARAÚJO, Oscar E. Enquistamentos étnicos. Revista do Arquivo Municipal. Vol. LXV, p. 227-246. 1940.

AZEVEDO, Fernando. A antropologia e a sociologia no Brasil. In: As Ciências Sociais no Brasil. SP: Edit. Melhoramentos, 1955. Vol. II, p. 353-399.

BACELLAR, Jeferson A. Sociologia da socio-antropologia do negro da Bahia. Anuário Antropológico/79. Tempo Brasileiro, 1981. pp. 261-276.

BASTIDE, Roger e FERNANDES, Florestan. Brancos e negros em São Paulo: ensaio sociológico sobre aspectos de formação, manifestações atuais e efeitos do preconceito de côr na sociedade paulistana. $2^{\text {a }}$ edição. SP: Companhia Editora Nacional, [1955] (1959).

BASTOS, Cristiana e CORDEIRO, Graça Índias. Desafios e metamorfoses da antropologia contemporânea: entrevista com Gilberto Velho. Etnográfica: Revista do Centro de Estudos de Antropologia Social, Vol. 1(2), p. 321-327. 1997.

BECKER, Howard S. Diálogos com Howard S. Becker. In: Uma teoria da ação coletiva. Trad. M. B. Nunes. RJ: Zahar, 1977. pp. 13-36.

BECKER, Howard S. Uma entrevista com Howard S. Becker. Estudos Históricos. Vol. 3 (5), p. 114-136. 1990.

BECKER, Howard S. A Escola de Chicago. Mana, vol. 2(2), p. 177-188. 1996.

BRESLAU, Daniel. L'Ecole de Chicago existe-t-elle?. Actes de la Recherche en Sciences Sociales. n. 74, p. 64-65. 1988a.

BRESLAU, Daniel. Robert Park et I'ecologie humaine. Actes de la Recherche en Sciences Sociales. n. 74, p. 55-63. 1988b.

BURGESS, Ernest W. O crescimento da cidade: introdução a um projeto de pesquisa. In: PIERSON, Donald (org). Estudos de ecologia humana: leituras de Sociologia e Antropologia Social. 2da. edição. Tomo I. SP: Livraria Martins Editora, [1923] 
1970. p. 353-368.

BULMER, Martin. The Chicago School of Sociology: Institutionalization, Diversity and the Rise of Sociological Theory. Chicago: University Chicago Press, 1984.

CAVALCANTI, Maria Láura V.C. Oracy Nogueira e a Antropologia no Brasil: o estudo do estigma e do preconceito racial. Revista Brasileira de Ciências Sociais. N. 31, p. 5-28. 1996a.

CAVALCANTI, Maria Láura V.C. Oracy Nogueira (1917-1996): uma biografia intelectual. Ciência e Trópico. Vol. 24, n. 1, p. 179-188. 1996b. (republicado em 1997. Boletim da ABA. N. 27, p. 26-29).

CAVALCANTI, Maria Láura V.C. Preconceito de marca, etnografia e relações raciais. Tempo Social. Vol. 11, n. 1, p. 97-110. 1999.

CASTRO, Marcos Luiz. Entre o Japão e o Brasil: a construção da nacionalidade na trajetória de vida de Hiroshi Saito. 1994. 170 p. Dissertação (Mestrado em Antropología Social). - Instituto de Filosofía e Ciências Humanas, Universidade Estadual de Campinas, UNICAMP, Campinas.

CENTRO Brasileiro de Pesquisas Educacionais. Projeto de pesquisa sobre os processos de industrialização e urbanização. Educação e Ciências Sociais, vol. 5, n. 11, p. 113-118. 1959.

COLE, Sally. Introduction: Ruth Landes in Brazil: Writing, Race and Gender in 1930s, American Anthropology. In: The City of Women. Albuquerque: University of New Mexico Press, 1994. p. VII-XXIV.

CONSORTE, Josildeth Gomes. Os estudos de comunidade no Brasil: uma viagem. In: FALEIROS, Maria Izabel Leme e CRESPO, Regina Aída (org.). Humanismo e compromisso: ensaios sobre Octavio lanni. SP: Editora da UNESP, 1996. p.51-68.

CORRÊA, Mariza. (Org.). História da Antropologia no Brasil (1930-1960): testemunhos: Emílio Willems e Donald Pierson. Campinas: Editora da UNICAMP/ Edições Vértice, 1987. Vol. I.

CORRÊA, Mariza. Traficantes do excêntrico: os antropólogos no Brasil dos anos 30 aos anos 60. Revista Brasileira de Ciências Sociais, vol. 3, n. 6, 79-98. 1988a. 
CORRÊA, Mariza. A revolução dos normalistas. Cadernos de Pesquisa, n. 66, p. 13-24. 1988b.

CORRÊA, Mariza. A antropologia no Brasil (1960-1980). In: História das Ciências Sociais no Brasil. Org. S. Miceli. SP: Sumaré/FAPESP. 1995.vol. 2, p. 25-106.

CORRÊA, Mariza. As ilusões da liberdade a escola de Nina Rodrigues e a Antropologia no Brasil. SP: FAPESP/USF, 1998.

COSER, Lewis. Sociological Theory from the Chicago Dominance to 1965. Annual Review of Anthropology. vol. 2, p. 145-160. 1976.

COSER, Lewis. Tendências americanas. In: BOTTOMORE, Tom e NISBET, Robert (org.). História da análise sociológica. Trad. W. Dutra. RJ: Zahar Editores. 1980.Cap. 8, p. 379-420.

COULON, Alain. A Escola de Chicago. Trad. T. Bueno. Campinas, SP: Papirus Editora, 1995.

DAVIS, Horace. O padrão de vida dos operários da cidade de São Paulo. Revista do Arquivo Municipal, vol. XII, p. 113-166. 1935.

EL FAR, Alessandra et.alii. Entevista com Ruth Cardoso. Cadernos de campo, n. 7, p. 149-166. 1998.

EUFRÁSIO, Mário. Estrutura urbana e ecologia humana: a Escola sociológica de Chicago (1915-1940). SP: Editora 34, 1999.

FARIS, Robert E.L. Chicago Sociology 1920-1932. Chicago: University Chicago Press, 1970.

FERNANDES, Florestan. As trocinhas do bom retiro: contribuição ao estudo folclórico e sociológico da cultura dos grupos infantis. In: Folclore e mudança social na cidade de São Paulo. SP: Editora Anhambi, 1961.

FERNANDES, Florestan. A sociologia no Brasil: contribuição para o estudo de sua formação e desenvolvimento. Petrópolis: Edit. Vozes, 1977. 
FONTENELLE, L. F. A comunidade no Brasil: um estudo tentativo para sua configuração. Revista de Ciências Sociais, vol. 2, n. 2, p. 5-14. 1971.

FREYRE, Gilberto. Sobrados e Mocambos: decadência do patriarcado rural e desenvolvimento do urbano. RJ: Instituto Nacional do Livro, [1936] (1977). Tomo 1:capítulo II, p. 30-66.

GALVÃO, Eduardo. Estudos sobre aculturação dos grupos indígenas. Revista de antropologia, vol. 5, n. 1, p. 67-74. 1957.

GIDDENS, Anthony. Sociologia: uma breve porém crítica introdução. Trad. A. Oliva e L. A. Cerqueira. RJ: Zahar Editores, 1984. p. 79 e 81.

GOITIA, Fernando Chueca. Breve história do urbanismo. Lisboa: Editorial Presença, 1982.

GOLDWASSER, Maria Julia. Estudos de comunidade: teoria e/ou método. Revista de Ciências Sociais, vol. V, n. 1, p. 60-81. 1974.

GRAFMEYER, Yves e JOSEPH, Issac. Présentation. In: GRAFMEYER, Yves (Org.). L'École de Chicago: Naissance de l'Écologie Urbain. Paris: Champ Urbain-Aubier, 1989. 255 p. p. 5-52.

GUIDI, M.LN. Elementos de análise dos estudos de comunidade realizados e publicados de 1946-1960. Revista de Educação e Ciências sociais, vol. 10, n. 19, p. 4-87. 1962.

GUIMARÃES, Antônio Sérgio. Racismo e anti-racismo no Brasil. Novos Estudos Cebrap, n. 43, p. 26-44. 1995.

GUIMARÃES, Antônio Sérgio. Cor, classes e status nos estudos de Pierson, Azevedo e Harris na Bahia: 1940-1960. In: MAIO, Marcos Chor e SANTOS, Ricardo Ventura (org). Raça, ciência e sociedade.RJ: Editora Fiocruz, 1996. p. 143-157.

GUIMARÃES, Antônio Sérgio. Baianos e paulistas 'duas escolas' de relações raciais?. Tempo Social, vol. 11, n. 1, p. 75-95. 1999a. 
GUIMARÃES, Antônio Sérgio. Raça e os estudos de relações raciais no Brasil. Novos Estudos Cebrap, n. 54, p. 147-156. 1999b.

HANNERZ, Ulf. Exploración de la ciudad: hacia una antropología urbana. Trad. I. Vermont e P. Villegas. México: Fondo de Cultura Económica, 1986.

HELLER, Frederico. História natural de uma rua suburbana. Sociologia, vol V, n. 3, p. 199-216. 1943.

HERMANN, Lucila. Grupos sociais de Guaratinguetá. Revista do Arquivo Municipal, vol. XLIX, p. 71-92. 1938.

HERMANN, Lucila. Estudo do desenvolvimento de São Paulo através da análise de uma radial: a estrada do café (1935). Revista do Arquivo Municipal, vol. XCIX, p. 7-44. 1944.

IANNI, Octavio. Estudo de comunidade e conhecimento científico. Revista de Antropologia, vol. 9, n. 1-2, p. 109-119. 1961.

KOFES, Suely. As pedras e o arco: os estudos de comunidade e a atualidade de antigas questões. In: FALEIROS, Maria Izabel Leme e CRESPO, Regina Aída (org.). Humanismo e compromisso: ensaios sobre Octavio lanni. SP: Editora da UNESP, 1996. p. 41-49.

KURTZ, Lester R. Evaluating Chicago Sociology: A Guide to the Literature with an Annoted Bibliography. Chicago: University Chicago Press, 1984.

LANDES, Ruth. A cidade das Mulheres. RJ: Civilização Brasileira, [1947] 1967.

LIMONGI, Fernando. Revista Sociologia a E.L.S.P. e o desenvolvimento da Sociologia em São Paulo (dois estudos). Série História das Ciências Sociais. FFLCHUSP. (1). 1987.

LIMONGI, Fernando. A Escola Livre de Sociologia e Política em São Paulo. In: MICELI, Sergio (org.). História das Ciências Sociais no Brasil. Vol. 1, n. 217-233. SP: IDESP-Editora Vértice, 1989. 
LINDNER, Rolf. The Reportage of Urban Culture: Robert Park and the Chicago School. Cambridge: Cambridge University Press, 1996.

LOWRIE, Samuel H. Origem da população da cidade de São Paulo e diferenciação das classes sociais. Revista do Arquivo Municipal, vol. XLIII, p. 195-212. 1938a.

LOWRIE, Samuel H. Pesquisa de padrão de vida dos operários da limpeza pública da municipalidade de São Paulo. Revista do Arquivo Municipal, vol. LI, p. 183310. 1938b.

MAGNANI, Jose Guilherme Cantor. O campo da antropologia. Cadernos de História de São Paulo, n. 1, p. 45-56. p. 48. 1992.

MANNHEIM, Karl. O problema sociológico das gerações. In: FORACCHI, Marialice Mencarini (org.). Mannheim. São Paulo: Ática, 1982. (Coleção Grandes Cientistas Sociais). p. 67-95.

MAIO, Marcos Chor. A história do projeto UNESCO: estudos raciais e Ciências Sociais no Brasil. 1997. 290 p. Tese (Doutorado em Sociologia). - Instituto Universitário de Pesquisas do Rio de Janeiro, IUPERJ, Rio de Janeiro.

MARTINDALE, Don. American Sociology Before World War II. Annual Review of Anthropology, vol. 2, p. 121-143. 1976.

MASSI, Fernanda Peixoto. Franceses e norteamericanos nas ciências sociais brasileiras (1930-1960). In: MICELI, Sergio (org.). História das Ciências Sociais no Brasil. SP: IDESP-Editora Vértice, 1989. Vol. 1, p. 410-459.

MENDOZA, Edgar S. G. Sociologia da Antropología urbana no Brasil: a década de 70. 2000. 325 p. Tese (Doutorado em Ciencias Sociais). - Instituto de Filosofia e Ciências Humanas, Universidade Estadual de Campinas, UNICAMP, Campinas. MOREIRA, M. Estudo sociodemográfico de comunidades. Revista de Antropologia, vol. II, n. 1-2, p. 29-39. 1963.

MOWRER, Ernest. El estudio ecológico de la ciudad. Revista Mexicana de Sociología, vol. V, p. 19-25. 1943. 
NOGUEIRA, Oracy. Distribuição residencial de operários de um estabelecimento industrial de São Paulo. Sociologia, vol. XI, n. 1, p. 32-53. 1949.

NOGUEIRA, Oracy. Os estudos de comunidade no Brasil. Revista de Antropologia, vol. 3, p. 95-103. 1955.

NOGUEIRA, Oracy. A Sociologia no Brasil. In: FERRI, Mário Guimarães e MOTOYAMA, Shozo (Coord.). História das Ciências no Brasil. São Paulo: EDUSPEPU-CNPq, 1981. vol. 3, p. 181-234.

NOGUEIRA, Oracy. Esboço de uma trajetória intelectual: depoimento. História, Ciências, Saúde. Manguinhos. Vol. II, n. 2, p. 119-134. 1995.

OLIVEIRA, Lúcia Lippi de. Donald Pierson e a sociologia no Brasil. BIB. RJ: ANPOCS. pp. 35-48; e Nogueira, Oracy. Donald Pierson e o desenvolvimento da Sociologia no Brasil. Universitas. n. 6/7, p. 331-342. 1987.

PARISSE, Lucien. Bibliografia cronológica sobre a Favela do Rio de Janeiro, a partir de 1940. América Latina, n. 3, p. 221-232. 1969.

PEARSE, Andrew. Notas sôbre a organização social de uma favela do Rio de Janeiro. Educação e Ciências Sociais, vol. 3, n 7, p. 9-32. 1958.

PEIRANO, Mariza. The Anthropology of Anthropology: the Brazilian Case. Tese de Doutorado, Harvard University, Cambridge Mass 1981. Republicada na Serie Antropologia. (110), Brasília: UnB-IH-DAN, 1991.

PIERSON, Donald. Recenseamento por quarteirões. Revista do Arquivo Municipal, vol. LXII, p. 173-175. 1939.

PIERSON, Donald. Habitações de São Paulo: estudo comparativo. Revista do Arquivo Municipal, vol. LXXXI, p. 199-238. 1942.

PIERSON, Donald. O estudo da cidade. Sociologia, vol. V, n. 4, p. 305-315. 1943.

PIERSON, Donald. Teoria e pesquisa em Sociologia. SP: Edições Melhoramentos, 1945. Vol. 30 da "Biblioteca de Educação"; a edição que consultei foi a 13 
reimpresão de 1971, (a última edição do livro foi a 18 edição revista em 1981). PIERSON, Donald. Ecologia humana. Sociologia, vol. IX, n. 2, p. 153-163. 1947. PIERSON, Donald. Exame crítico da ecologia humana. Sociologia, vol. X, n. 4, p. 227-241. 1948

PIERSON, Donald (org.) Estudos de ecologia humana: leituras de Sociologia e Antropologia Social. 2da. edição. Tomo I. SP: Livraria Martins Editóra, [1948] 1970.

PIERSON, Donald. Brancos e pretos na Bahia: estudo de contato racial. 2da. edição. SP: Companhia Editora Nacional, [1942] (1971).

PIERSON, Donald. Apêndice D: Estudo de contato racial no Brasil: procedimentos de pesquisa. (ibid.) 1971. p. 390-398.

QUINN, James. A hipótese de zonas de Burgess e seus críticos. In: PIERSON, Donald (org). Estudos de ecologia humana: leituras de Sociologia e Antropologia social. 2da. edição. Tomo I. SP: Livraria Martins Editóra, [1940] 1970. p. 369-381.

RAMOS, Arthur. Introdução à primeira edição brasileira. In: Brancos e pretos na Bahia: estudo de contato racial. 2da. edição. SP: Companhia Editora Nacional, (1971). p. 67-70.

REISSMAN, Leonard. The Urban Process: Cities in Industrial Societies. NY: The Free Press, 1969.

RODRIGUES, Nina. Os africanos no Brasil. 6ta. edição. Brasília: Editora da Universidade de Brasília, [1932] (1982).

SAITO, Hiroshi. O suicídio entre os imigrantes japonêses e seus descendentes no Estado de São Paulo. Sociologia, vol. XV, n. 2, p. 109-130. 1953.

SAITO, Hiroshi. O japonês no Brasil: estudo de mobilidade e fixação. SP: Editora Sociologia e Política, 1961. 
SCHADEN, Egon. O estudo socioantropológico da aculturação dos alemães no Brasil. In: Introdução ao estudo da antropologia no Brasil. Encontro internacional de estudos brasileiros, I Seminário de estudos brasileiros (São Paulo, 13 a 25 de setembro), Egon Schaden (Coord). 2 Vols. 1971b.

SHORT, James. Introduction. In: The Social Fabric of the Metropolis: Contributions of the Chicago School of Urban Sociology. Chicago: University Chicago Press, 1971. p. xi-xlvi.

SMITH, Dennis. The Chicago School: A liberal Critic of Capitalism. New York: St. Martin's Press, 1988.

SOUZA, Rafael de Paula. Contribuição à etnologia paulista. Revista do Arquivo Municipal, vol. XXXI, p. 95-105. 1937.

TIRYAKIAN, Edward A. The significance of Schools in the Development of Sociology. In: SNIZEK, W. et.alii. (eds). Contemporary Issues in Theory and Research: a Metasociological Perspective. London:Greenwood Press, 1979. p. 211-233.

URBAN LIFE: Special Issue. The Chicago School: The tradition and the legacy. Vol. 11, n. 4. 1983.

VILA NOVA, Sebastião. Sociologias \& pós-Sociologias em Gilberto Freyre: algumas fontes e afinidades teóricas e metodológicas do seu pensamento. Recife: Editora Massangana-Fundação Joaquim Nabuco, 1995.

VILA NOVA, Sebastião. O singular e o universal nos estudos de comunidade. In: FALEIROS, Maria Izabel Leme e CRESPO, Regina Aída (org.). Humanismo e compromisso: ensaios sobre Octavio lanni. SP: Editora da UNESP, 1996. p. 69-76.

VILA NOVA, Sebastião. Donald Pierson e a Escola de Chicago na Sociologia brasileira: entre humanistas e messiânicos. Lisboa: Vega Universidade, 1998.

WAGLEY, Charles. Estudos de comunidade no Brasil sob perspectiva nacional. Sociologia, vol. 16 n. 2, p. 3-22. 1954.

WAGLEY, Charles. Brazilian Community Studies: A Methodological Evaluation. In: 
Anais do XXXI Coongresso Internacional de Americanistas. 23-28 de agosto de 1954. H. Baldus (org. e pub.). SP: Editora Anhembi, 1955. Vol I, p. 257-382.

WAGLEY, Charles. e AZEVEDO, Thales de. Sobre métodos de campo no estudo de comunidades. Revista do Museu Paulista, (Nova série) vol. V, p. 227-237. 1951.

WILEY, Norbert. The Rise and Fall of Dominating Theories in American Sociology. In: SNIZEK, W. et.alii. (eds). Contemporary Issues in Theory and Research: a Metasociological Perspective. London: Greenwood Press, 1979. p.47-79.

WILLEMS, Emílio. Contribuição para uma Sociologia da vizinhança. Sociologia, vol. 3, n. 1, p. 29-43. 1941.

WILLEMS, Emílio. A aculturação dos alemães no Brasil: estudo antropológico dos imigrantes alemães e seus descendentes no Brasil. SP: Companhia Editora Nacional, 1946.

WOORTMANN, Klaas. A antropologia brasileira e os estudos de comunidade. Universitas, n. 11, p. 103-140. 1972.

XIDIEH, Osvaldo E. Subúrbio. Revista do Arquivo Municipal, vol. CXIV, p. 173184. 1947.

ZICCARDI, Alícia. De la ecología urbana al poder local: (cinco décadas de estudios urbanos). Revista mexicana de sociologia, vol. LI, n. 1, p. 275-306. 1989. 


\section{Resumo}

O artigo, em termos amplos, trata da influência de Donald Pierson, formado na Escola Sociológica de Chicago, que teve maior repercussão na pesquisa urbana no Brasil, nos anos 30 e 50, tanto na Sociologia quanto na Antropologia, na cidade de São Paulo. A pesquisa urbana no Brasil tanto sociológica quanto antropológica teve referenciais teóricos que deixaram sua marcas nos trabalhos da época. No meu argumento, se pensarmos nos campos científicos da Antropologia e da Sociologia Urbana no Brasil, uma das tendências teóricas em um momento histórico e teórico foi a Escola Sociológica de Chicago. Um resgate de pesquisas precursoras de estudos urbanos na cidade de São Paulo poderiam comprovar a influência da Escola de Chicago. Apesar de serem pesquisas isoladas, enfatizaram fortemente questões propriamente urbanas. Seria arriscado defini-las nesta época como uma Sociologia Urbana propriamente dita, em São Paulo. O motivo de trazê-las é demonstrar que realmente foram um antecedente dos estudos urbanos no Brasil, entre 1935-1950. Assim, posso dizer que a Sociologia da Escola de Chicago teve influência em três campos no Brasil: a) relações raciais (negros, brancos e imigrantes), b) estudos de comunidade (pequenas cidades rurais) e c) estudos na cidade (principalmente São Paulo). Portanto, estou pensando a cidade de São Paulo como um cenário em termos gerais, como uma agenda de pesquisa institucional nos anos 35-50. Entre as poucas e modestas pesquisas de Sociologia na cidade de São Paulo tomada como objeto de estudo, foi feita uma etnografia na cidade ou uma etnografia urbana diferente dos clássicos estudos de comunidades em pequenas cidades rurais. Temos inicialmente oito trabalhos que foram publicados principalmente como artigos em revistas, sendo o objeto de pesquisa alguns bairros da cidade ou em outras cidades. O ponto central do artigo está na ampla bibliografia que foi encontrada, e apresentada no final do texto sobre a influência da Escola de Chicago e sua repercussão no Brasil.

Palavras-chave: Donald Pierson, Escola Sociológica de Chicago, Sociologia urbana, Estudos urbanos na cidade de São Paulo, Etnografia urbana 


\section{Donald Pierson and the Sociological School of Chicago in Brazil: urban studies in the city of São Paulo (1935-1950)}

\section{Edgar S. G. Mendoza}

This paper is an overview of the influence of Donald Pierson, formed in the Sociological School of Chicago, which had more repercussion on urban research in Brazil in the 1930s and 1950s, both within Sociology and Anthropology, in the city of São Paulo. Urban research in Brazil - both sociological and anthropological - had theoretical references that left their marks on the works of that time. According to my argument, regarding the scientific fields of anthropology and urban Sociology in Brazil, one of the theoretical trends in a certain historical and theoretical context was the Sociological School of Chicago. Revisiting pioneer urban studies in São Paulo could assert the influence of the School of Chicago. In spite of being isolated studies, they have strongly stressed properly urban issues. It would be risky to define them these days as Urban Sociology in its own right, in São Paulo. The reason for bringing them up is to demonstrate that they really represented antecedents to urban studies in Brazil between 1035-1950. Therefore, I can say that the sociology of the School of Chicago had its impact on three fields in Brazil: a) racial relations (blacks, whites, and immigrants); b) community studies (small rural towns); and c) studies in the city (especially in São Paulo). Therefore, I think of the city of São Paulo as a scenario in general terms, as an agenda for institutional research in 1935-1950. Among the few and modest sociology studies having the city of São Paulo as their object, an ethnography of the city or urban ethnography was conducted that was different from classic studies on communities or small rural towns. Initially, we have eight works published mainly as journal articles, and their research object was some neighborhoods in São Paulo or other cities. The main feature of the article is the extensive bibliography found and presented at the end of the text, about the impact of the Scholl of Chicago and its repercussion in Brazil.

Key words: Donald Pierson, Sociological School of Chicago, urban sociology, urban Studies in the city of São Paulo, urban ethnography 